\title{
Decolonising the mind: Mathematics teachers explore possibilities for indigenising the school curriculum
}

\section{Vimolan Mudaly}

Mathematics and Computer Science Cluster, School of Education, University of KwaZulu-Natal, Durban, South Africa

Mudalyv@ukzn.ac.za

http://orcid.org/0000-0003-3570-1256

(Received: 10 May 2018; accepted: 31 October 2018)

\section{Abstract}

More than twenty years after the ushering in of a democratic order, South African universities remain complicit in driving colonial ideals through curricula (de Beer \& Petersen, 2016; Fataar, 2018). These curricula position Western people as superior individuals who seek to help disadvantaged non-westerners who are weak, helpless, and dependent, and who cannot survive without aid from Western philanthropists. In this paper, I heed the call to re-orient curricula away from knowledge systems that have been used to devalue indigenous African people by othering them in the country of their birth. I do this by creating an opportunity for practising teachers of different races, all of whom were part of a postgraduate module, to reconceptualise the current school curriculum by placing African learners and their contexts at the centre of teaching. In this qualitative study, 20 practising teachers were purposively selected to draw on their own visions and talents and those of their multiracial learners to develop possibilities for indigenising the teaching and learning of mathematics. This was aimed at decolonising their minds by transforming their understanding of themselves and encouraging them to tap into their critical thinking and analytical skills when they were examining the current school curricula. To accomplish this, teachers studied the Curriculum Assessment Policy Statements (CAPS) in mathematics, and developed units of work aimed at valuing indigenous knowledge. Data was drawn from teachers' portfolios of evidence that included photo-narratives and reflections on the unit of work they created. Through thematic analysis the findings revealed that teachers and their learners tapped into resources in and outside the school and engaged in work that was responsive to their own needs. However, the exercise demonstrated that these teachers found it difficult to depart from the comfort of the factual mathematics they taught to include indigenous links from contexts around them. This was clear in their attempt to produce contrived associations with the knowledge from CAPS.

Keywords: decolonisation, indigenisation, curriculum, mathematics education

\section{Introduction}

In the global knowledge economy, dominant forms of knowledge are attributed to Western sources (Kaya \& Seleti, 2013; Mbembe, 2015; Studley, 1998). A closer look at the ubiquitous knowledge frameworks that are credited to Western societies reveals that this knowledge has not been formed independently of the rest of the world (Connell, 2016). Postcolonial and 
other non-western societies have been the source of data for many disciplines. The scientific analysis of this knowledge to which Connell (2016) refers as the "theory part of the production of knowledge" (p. 2) occurs mainly in research institutions in the US and in Western European countries. She refers to these societies as the metropole of knowledge production that is positioned as epistemologically superior to knowledge produced by other societies. Higher education institutions (HEIs) are complicit in perpetuating the myth that the only episteme that is worth mastering is that which is framed within the theories of the metropole (Connell, 2016; Heleta, 2016).

In South Africa, the institutional culture and structure of HEIs are largely Eurocentric (Heleta, 2016) and these are the institutions that produce the teachers who are employed to teach at the schools. Despite visions of a just and equitable life for all at the dawn of the era of political freedom, South African HEIs have continued to perpetuate inequality by valuing colonial ideals (Badat, 2008; Department of Higher Education and Training, 2015). While transformation, equality, and equity are professed through the vision, mission, and policies that govern South African HEIs, the enacted epistemological traditions remain firmly rooted in Eurocentric curricula, teaching, and research (Heleta, 2016; Mbembe, 2016). In order to decolonise the current South African school curriculum, the processes of rethinking, reframing, and reconstructing existing colonial curricula need to be initiated. Before these processes can be advanced, however, increasing awareness about the epistemic violence that lies in the wake of colonial curricula is crucial. Epistemic violence manifests in the form of Western knowledge being seen to be superior and universal and the erasure of intellectual and cultural contributions of non-western societies to the world at large (Heleta, 2016). The consequent denigration of non-western people is of crucial concern and this should underpin any decolonising discourse.

One way of addressing this epistemic violence is to foreground the indigenous voices and practices of previously marginalised groups. In this paper, I refer to indigenisation as the act of adapting and transforming the educational landscape to incorporate indigenous knowledge into lessons on mathematics as a way of teaching relevant concepts and ideas. Indigenisation encourages a culturally responsive curriculum that addresses the needs, knowledge, and cultures of local communities. This does not imply the creation of completely new knowledge systems but the inclusion of culturally relevant practices, materials, and knowledge into the teaching process that would enhance the understanding of particular concepts. In my consideration of indigenisation from the point of view of a teacher of mathematics, I draw on Bernstein's (1996) belief that recontextualisation is concerned with the "principle for appropriating other discourses and bringing them into a special relation with each other for the purpose of their selective transmission and acquisition" (p. 47). I do not argue for appropriation since that would indicate a kind of annexation of someone else's knowledge. However, I believe that the re-appropriation of indigenous knowledge that has been relegated to the realms of irrelevancy through the process of recognising that only Western and European knowledge is both useful and germane, is essential to the decolonising process. 


\section{Teaching mathematics}

When one is teaching mathematical knowledge, there are important issues that must be considered (see Figure 1). The colonial/westernised knowledge is necessary for learners to develop into productive human beings. This is needed so that they can function in society, the workplace, or at educational institutions. All the factual knowledge becomes necessary for progress in today's society. Dependent on the learner's trajectory at work or in her or his studies, certain aspects of the curriculum are very important. But, to a large extent, most mathematics is taught in unfamiliar contexts; I suggest that colonial mathematics cannot be isolated from indigenous knowledge that allows for a better understanding of colonial mathematics by providing contexts that are familiar to the learners. Often, indigenous knowledge is necessary for living but, because of modernisation, there is a gradually increasing sense that indigenous knowledge in academic contexts is becoming unnecessary.

\section{Mathematical Knowledge}

(Pure, conceptual, scientific)

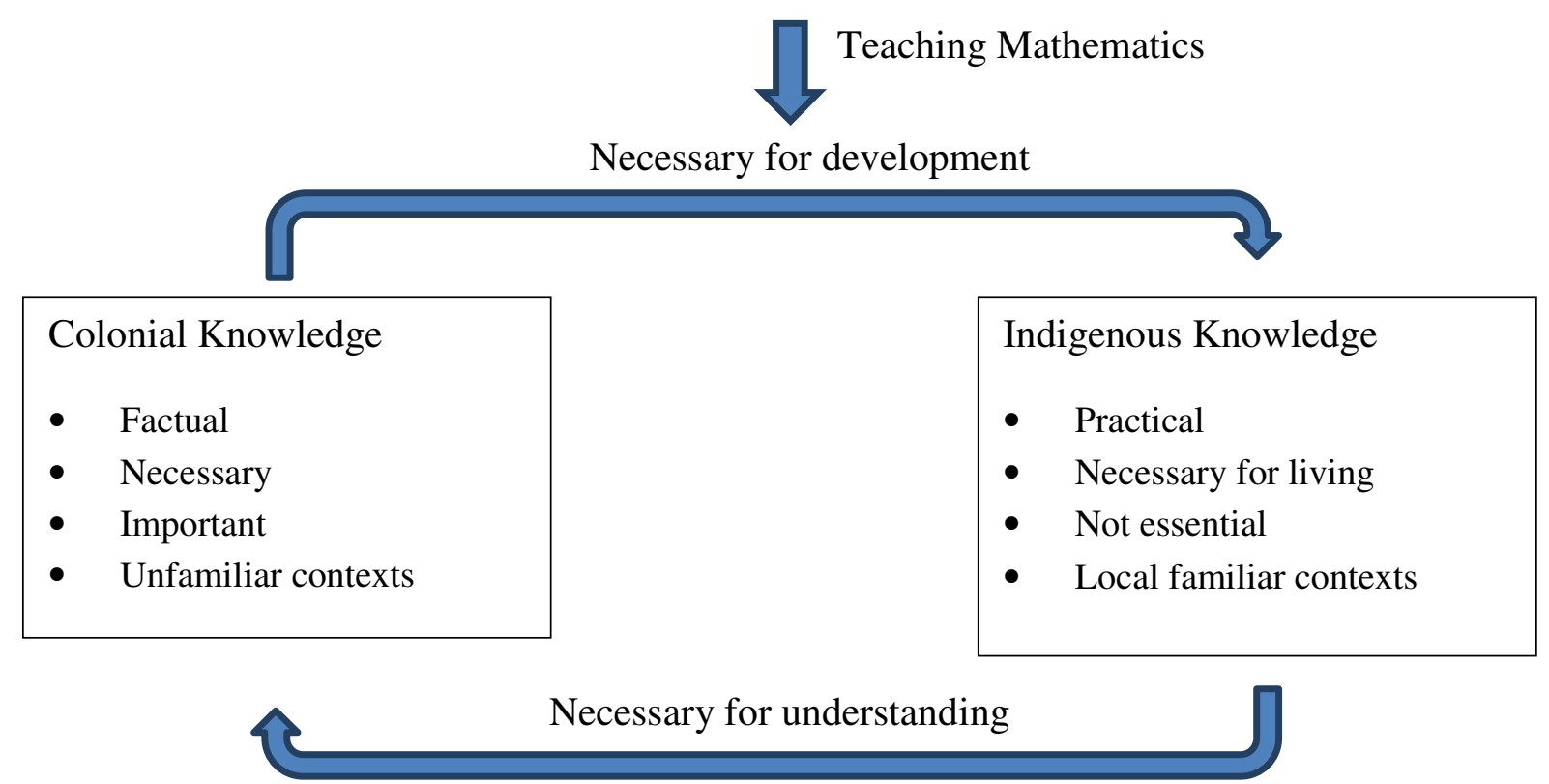

Figure 1: Summary of the recontextualising process

\section{The need for engagement with Indigenous Knowledge}

The impetus in South Africa after 1994 has been towards preserving indigenous knowledge and finding ways of relating the current content to that found in traditional and cultural contexts. The Department of Science and Technology (DST) (2004) stated that "the affirmation of African cultural values in the face of globalisation [is] a clear imperative given the need to promote a positive African identity" (p. 9). The DST further motivated for this notion of Indigenous Knowledge Systems by stating that 
the Indigenous Knowledge Systems (IKS) developed and maintained by South Africa's indigenous peoples pervades the lives and the belief systems of a large proportion of the country's population. Such indigenous knowledge manifests itself in areas ranging from cultural and religious ceremonies to agricultural practices and health interventions. (p. 10)

The significance of IKS was further emphasised in CAPS (Department of Basic Education, 2011). Here we read that one of the important principles of the curriculum is "valuing indigenous knowledge systems: acknowledging the rich history and heritage of this country as important contributors to nurturing the values contained in the Constitution" (p. 6).

These are important principles, but there is not much clarity provided as to how a teacher or teacher educator can include such knowledge in the mathematics curricula. In fact, despite this principle of valuing IKS, no other reference is made to this in the mathematics CAPS documents although a number of references are made to IKS in the Physical Science and Life Sciences CAPS documents. The silence in the document relating to IKS is a form of subtle exclusion and does not convey the importance of learners developing their own knowledge using the social and cultural artefacts, ceremonies, and beliefs of their indigenous communities. Clearly, the absence of the IKS bricolage in the mathematics curriculum may indicate a perverse belief that mathematics is pure and is immune to extraneous influences, including cultural and social factors. As Kincheloe (2007) has said, "Pushing to a new conceptual terrain, such an eclectic process raises numerous issues that researchers must deal with in order to maintain theoretical coherence and epistemological innovation" (p. 945). Mathematics education must also show such epistemological innovation through a creative search for, and inclusion of, diverse mathematics that incorporate the multilogicality, to use Kincheloe's word from the title of his chapter, of the discipline.

There has been a lack of cultural mathematics in the South African education system where knowledge is harvested from outside the national context. This is evidenced through a scrutiny of CAPS (DoE, 2011) documents in which the absence of mention of authentic indigenous mathematics is easily observable. The CAPS mathematics curriculum relies heavily on the knowledge that emanates from Eurocentric contexts. This is in keeping, still, with Joseph's (1987) statement, made three decades ago, that "there exists a widespread Eurocentric bias in the production, dissemination and evaluation of scientific knowledge" ( $\mathrm{p}$. 13). Much of the South African school mathematics curriculum is based on this knowledge and is located in specific topics such as Euclidean geometry, calculus, probability, and so on. Vithal and Volmink (2005) have also recognised that "curriculum approaches that have shaped curriculum development in Western countries have also left their mark on mathematics curricula in South Africa, albeit in the form of curriculum changes that have often followed uncritically the loudest fad from the West" (p. 3). There are few arguments that can be cast against the value of our current mathematical knowledge given that it is appropriate and useful for the purposes of the South African learner who endeavours to pursue mathematics into universities, nationally and internationally. However, mathematics should not be available exclusively to a small group of learners. Most South African learners 
do not actualise the dream of a university degree and they exit school without recognising the value of a recontextualised, imported mathematics.

Furthermore, the argument for a recontextualised curriculum does not negate the value of Western and European mathematics but it does explore the possibility of reconceptualising mathematics in local contexts. It would be impossible to discover all mathematics knowledge in local contexts because mathematics developed through the interactions of global endeavours. No single nation can claim the rights to all mathematical knowledge and neither can anyone deny that all mathematics is dependent on the axiomatic findings of earlier or contemporary mathematicians.

So, in arguing for indigenisation and a recontextualised curriculum, we cannot ignore global demands and global advances. Despite the strong link to cultural practices, South African society has experienced tremendous change (technological, political, economic, and educational). These changes necessitate that we adapt and transform our goals constantly for the future. This does not mean that in keeping our eye on global advancements we have to eradicate local knowledge. This may seem to be paradoxical but global advancement does not have to eliminate local factors that promote understanding and identification of concepts. The most important point here is that recontextualising mathematics should offer opportunities for learners to identify different ways of understanding the same concept. Modernity does not destroy antiquity; it offers, quite simply, new possibilities. Bernstein's idea of the "pedagogization of society" that alludes to the fact that all knowledge is "fluid, changeable and changing" (as cited in Young, 1993, p. 132) is pertinent here. Knowledge may change but the way it is understood can easily be indigenised and recontextualised. The vehicle through which knowledge is conveyed or comprehended can be grounded in contexts that are familiar to the learner.

My empirical research attempts to mitigate the effects of the silence in CAPS about the value of indigenous knowledge in the teaching and learning of mathematics. I attempted to determine mathematics teachers' views about a colonised curriculum and the effects of it on their learners and I sought to establish whether mathematics teachers could find relevant knowledge and strategies to deliver a decolonised curriculum.

\section{Methodology}

The sample was purposively selected because only mathematics students who were registered for the Curriculum Development in Science and Mathematics Education module as part of the Bachelor of Education Honours programme were chosen. All 20 participants who volunteered were teachers of mathematics. It was expected that they would have a good knowledge of the CAPS document. Selecting these participants was ideal because they were engaged in a curriculum module, they were teaching at different schools, and they came from a wide variety of demographic contexts. The participants were exposed to various topics in their module related to the curriculum and its development, including decolonisation. Before they began with the project, they were asked to work in pairs and read all the articles 
provided in their course pack. Thereafter, the respondents had to produce an individual portfolio that included two lesson plans based on decolonised mathematics, their reflections on their lessons, and a report using photo-narratives as a methodology. They were given eight weeks to identify specific topics that they thought ideal to demonstrate how mathematics could be decolonised and to produce the portfolio. The pairing of the participants was simply a convenient strategy to afford them different experiences, values, and knowledge in an opportunity to come together and agree on a joint presentation. Once the participants had developed their lesson plans, they were expected to deliver the lessons in their mathematics classrooms and generate a report that had to include photo-narratives. Their reflections on the lessons were an important part of the portfolio.

This study was framed within the interpretivist paradigm because there was a need to understand how these participants (all practising teachers, as mentioned above) could become sensitised to colonial elements in the South African school curriculum. Furthermore, this research prompted them to design lessons to decolonise these elements (see Appendix A). In creating a response for this assessment task, the participants had to interrogate the existing CAPS curriculum, materials in the form of textbooks and other resources, and any other policy documents available to them in order to identify colonial influences. After recognising these influences, they had to design lessons and activities that showed that they could negate the effects of these oppressive influences.

Their portfolios were a useful research tool because it allowed me to acquire information from the participants that may not have been easily accessible via an interview, observation, or questionnaire. Portfolios allow for the gathering of evidence from personal and other sources specifically to address a given problem or task. The portfolios were extensive and were comprised of relevant literature, the personal reflections of the respondents, photonarratives, and lesson plans. They also afforded the participants sufficient time to engage with the topics they chose and were designed to encourage the participants to engage with material that is current and controversial. As Herman and Winters (1994) have reminded us, "Well-designed portfolios represent important, contextualized learning that requires complex thinking and expressive skills" (as cited in Barrett, 2007, p. 2).

\section{Findings, Data analysis, and discussion}

In general, these practicing teachers, including some from African and Indian communities, could not identify aspects of a colonised curriculum, so they did not know how they could easily decolonise it. Many of their responses were superficial and they provided examples and solutions that appeared to be coerced and contrived.

The themes emerged from the data during the analysis and were not predetermined. All the names of the participants are pseudonyms in order to protect their identities. 


\section{Decolonisation through a constructivist approach}

Zuma, a participant from a school in a black African township, felt that black Africans used to be socialised and educated in African cultural contexts. Colonial rule destroyed this process and gradually the indigenous systems began to erode. The extent to which this is true is demonstrated in the examples chosen by these participants. Whenever they attempted to illustrate the use of indigenous knowledge in mathematics, the only example they chose was the cylindrical hut with a conical thatched roof. Only one other participant located the cattle kraal as another appropriate example.

The response of Gese, another participant from a similar township school as Zuma's, to decolonising the curriculum was simply to change the names of the characters or the context in the way the problem was worded. He referred specifically to a problem that he chose to demonstrate his argument. He claimed that using an Afrikaner name in the problem indicated a colonial mentality. He felt that the white learners could easily identify with the name while the black learners would become demotivated. This the example that he quoted.

Siyabonga works for a fencing company. A customer called this morning, wanting to fence in his 1320 square-metre garden. He ordered 148 metres of fencing, but Siyabonga forgot to ask him for the width and length of the garden. But Siyabonga doesn't want the customer to think that he is an idiot, so he asks Mr Botha to complete the calculation for him. What are the dimensions?

This is a simplistic argument because the changes suggested do not promote understanding; they serve only to create greater identification with the context and characters. He further argued that the language used in the problem represented the colonial intruders when he claimed that "the words that they use are known mainly by those trespassers who ensure that their children will benefit." When asked to explain his claim he could provide no justification.

These respondents felt that we need to change something to allow for the learners' identification with the concept. In a constructive sense, for the learner to make new conceptual connections, old schema must be tapped. These learners have to identify with that which they know so that they can move towards what is unknown. This has implications for curriculum developers and pedagogy. First, curriculum developers must note that by recontextualising the school curriculum, by associating the current mathematics with local contexts there is then the possibility for greater understanding. Second, the pedagogical implications are evident. There is a need for teachers to become acutely aware of vast possibilities for the teaching of mathematics by connecting to indigenous knowledge from local communities. 


\section{Decolonising through using indigenous resources, practices, and settings/contexts}

Some participants felt that indigenous resources, practices, and contexts provide the ideal platform for decolonising the current curriculum. Proteas, another respondent, claimed that learners working individually is a colonial practice because group work is an African tradition. This may be true when viewed from the perspective of Ubuntu. However, group work has long been a practice of Western societies and much research has been done in this respect. Proteas did acknowledge, though, that currently in South Africa "the curriculum fails to relate mathematics to the learners' social and cultural practices." As a teacher, he recognised the need to indigenise the curriculum by "locating mathematics into a wide range of traditional practices that learners can identify with." This is exactly what Kincheloe (2011) appears to have had in mind when he said that "the tendency in Cartesian-Newtonian thinking is to erase mutualism's bonus of insight in the abstraction of the object of inquiry from the processes and contexts of which it is a part" (p. 341).

Nombu, a participant from an urban township, used the example of a kraal (see Figures 2 and 3). She did so because a kraal is arranged in a circular formation. Again, this is based on an example from a rural community and there is a possibility that urban youth who have not had the experience of visiting an African farm may not easily identify with this example.

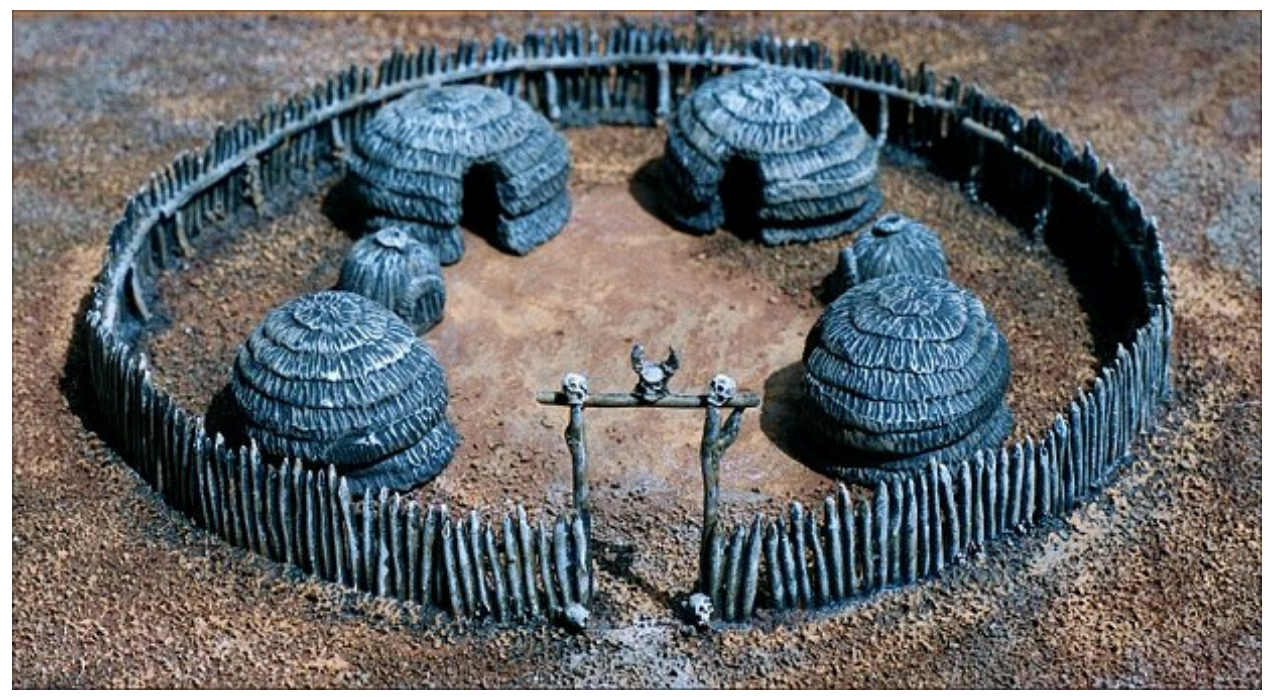

Figure 2: A model of a Zulu Kraal (retrieved from http://www.warrioronline.demon.co.uk/gallery/jpg/15/15_zulu/kraal3.jpg) 


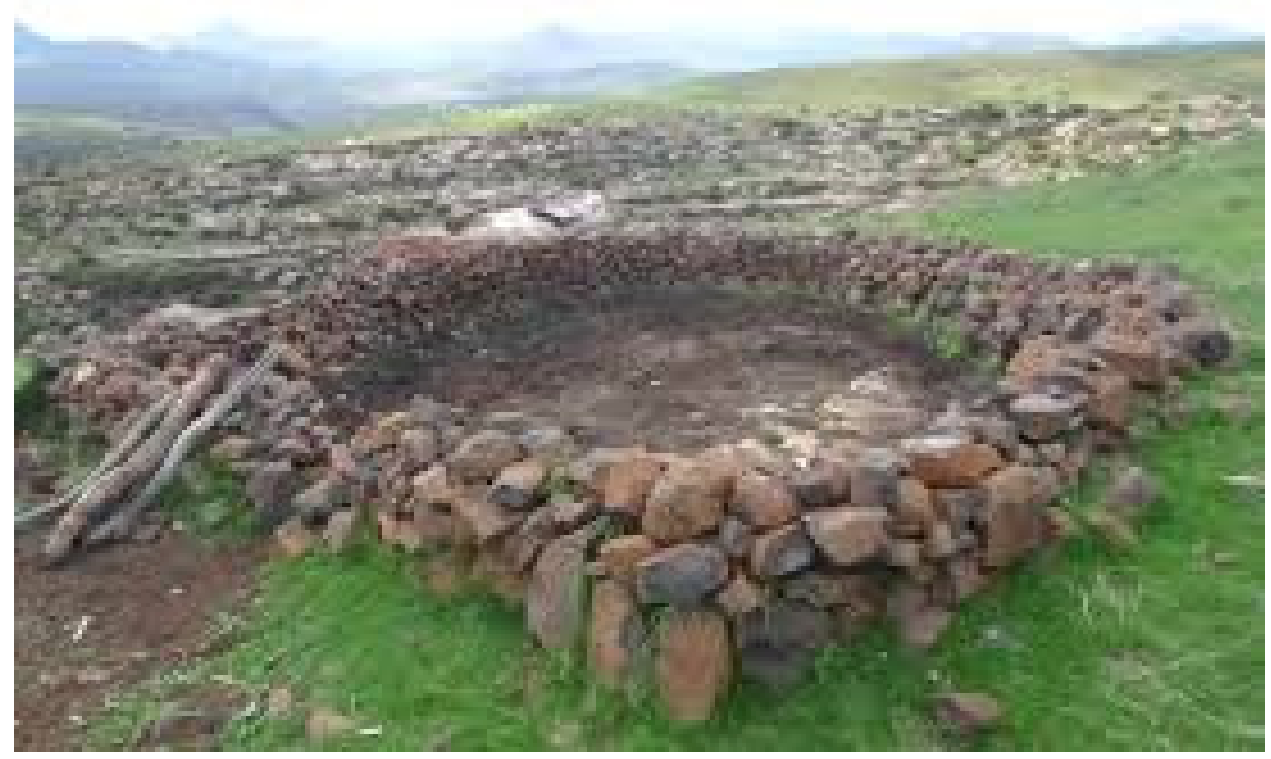

Figure 3: A cattle kraal (retrieved from: https://encrypted-

tbn0.gstatic.com/images?q=tbn:ANd9GcSjVTeHURJMhXBQiFnoF30IIAOkTOUiRJqS8yVcXvWwgz7UZ1ZI)

Shivanie felt that by excluding African contexts we impose Western ideologies on learners. This, she claimed, may be the reason for learner demotivation. They cannot see the relevance of the work and struggle to see how a Westernised mathematics will be beneficial to them. Shivanie then tried to link the parabola to the indigenous game called Kgati (which involves two players swinging a skipping rope and the third attempting to skip without falling). At many points during the swinging motion, the rope resembled a parabola. This was a rather tenuous relationship and because the motion of the rope cannot be frozen, it would have been difficult for the learners to make the connection between the game action and the concept of a parabola.

Besides the indigenous game, Kgati, Shivanie provided the example of the traditional South African meal called potjiekos ${ }^{1}$ (Figure 4). Although not an African meal it is still a traditional delicacy cooked in a three-legged pot. The quantities of the ingredients could easily be related to linear and quadratic functions. She also used traditional basket weaving as a means of depicting the shape of the parabola (Figure 5). This was used only to illustrate the shape of the graph. 


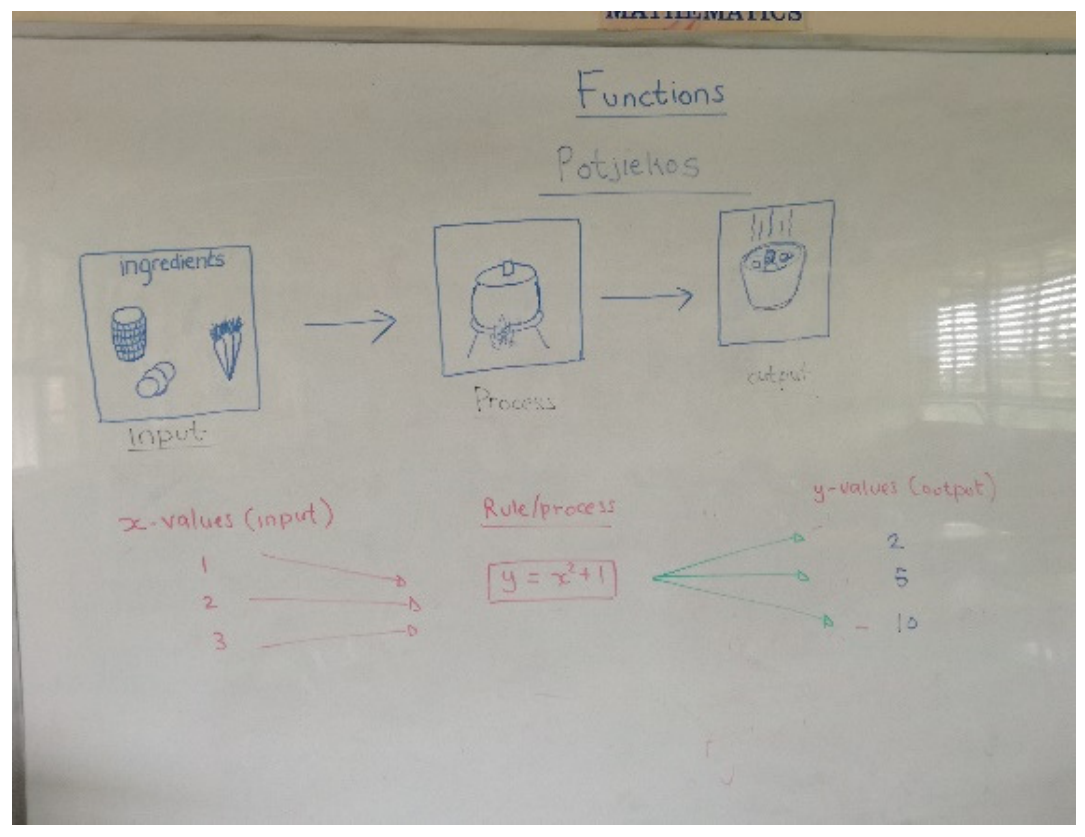

Figure 4: The use of the potjiekos example
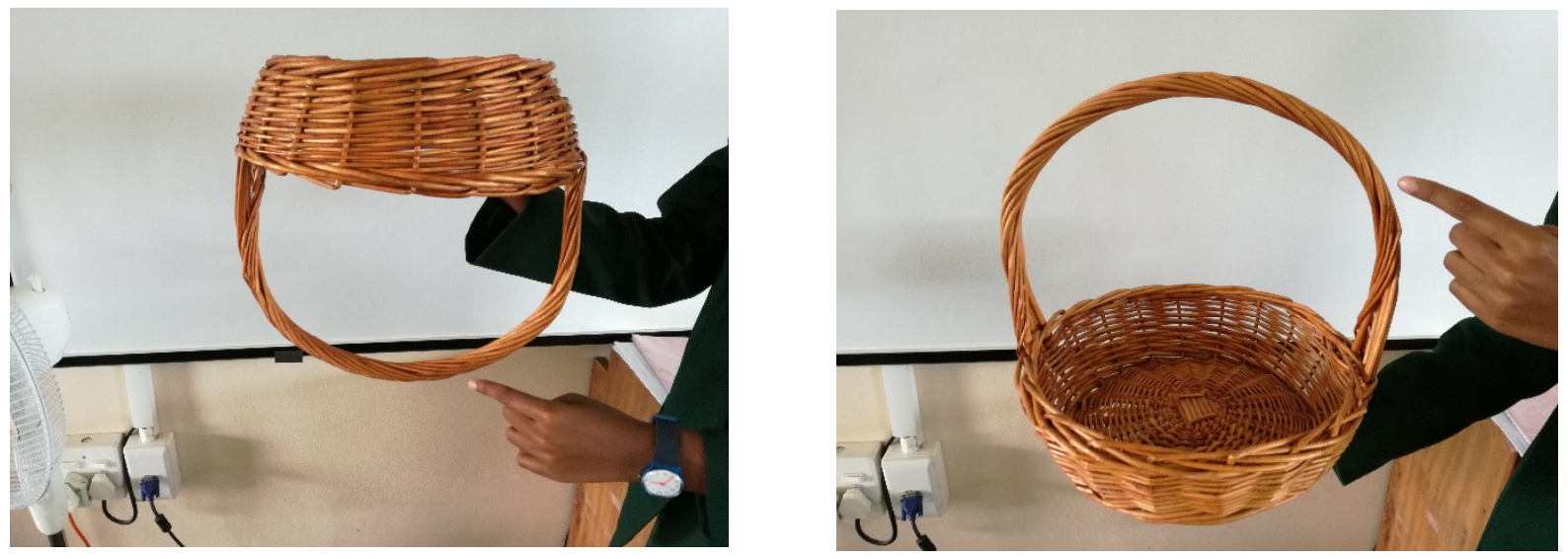

Figure 5: The use of the handle of a woven basket to illustrate the parabola graph

\section{Impossibility of decolonising the Math curriculum}

Another participant, Dube, claimed that "mathematical knowledge is fixed, and cannot be changed because problems give rise to a single solution." Dube's claim is challenged by Cobb (1986), who questioned the claim that mathematics is a superior science that exists entirely on its own when he stated that "beliefs are an essential aspect of meaning making in general and of mathematical meaning making in particular" (p. 2). He contended that "cognition is necessarily contextually bounded" and presented an argument that there is an "intimate relationship between contexts, goals, and beliefs" (p. 2). Also, the idea of a single solution can be debated but it is not the solution that is indigenised; it is the context used to increase understanding of the mathematical concept itself that is significant. Dube further argued that mathematics and its language is already difficult and including local contexts may confuse the learners. When asked for clarification it was clear that he felt that "it was too much work" to try to relate the mathematics to social and cultural practices. However, he did 
acknowledge that the pictures used in mathematics texts could be used to indigenise the subject.

\section{Creating possibilities for decolonising the Math Curriculum}

Dube's lesson plan included the aspect of calculating volume and he used a hypothetical example of a rectangular prism. When asked whether local communities possessed containers to store water, he was quick to see how he could have related his exercise to those experiences of water containers, like buckets, that learners already have.

It was evident that these respondents were resistant to change, despite the fact that they were themselves subservient to colonial ways in their study of mathematics. This resonates with the view that when the colonisers left, they walked out of our country but not out of our minds. They knew about African traditions and the effects of colonial education. Thuma, a respondent, showed evidence of this. Initially she said,

The practice of being one with nature amongst Africans has been the only method that indigenous people learn. The environment serves as their place of learning and discovery, it fed them, it sheltered them, and provided spaces for spiritual refuge. Indigenous people therefore were more attuned to nature for their survival. This is in contrast to what is advocated by the Western or Eurocentric model of education.

However, after attempting to plan and teach her lessons, she concluded that

the act of decolonising could not be accomplished in just a few lessons. This is a revolutionary concept requiring a paradigm shift in how curriculum planners, subject advisors, teachers and learners interact with and consume this knowledge from the African continent.

Phatha demonstrated a better understanding of this idea of a decontextualized indigenised curriculum when he said,

Building on indigenous knowledge systems and on what students are already familiar with, moving from the known to the unknown, is one of the strategies that can be used to decolonise a mathematical concept.

He cited Barwell (2005) who claimed that indigenous knowledge can be included when the educator makes connections to a wide range of differing contexts (daily activities, traditional practices, and activities in the workplace) and integrates learning related to mathematics and other subject areas into projects and assignments. He used the example of the shape of some African homes - the rondavel. Essentially, this is comprised of a cylindrical building with a conical roof. Patha claimed that even the paintings on the walls offer useful teaching points. He said that taking a two-dimensional picture of the rondavel can present the teacher with genuine contextual material for teaching. First, the learners identify with the rondavel since many have stayed in one of these structures. Also, this shape is used in a number of tourist places so most South Africans are familiar with it. The second important point to note that in 
a two-dimensional picture the roof looks like a triangle and many properties of a triangle can be discussed. Third, the base of the wall would form a circle and many concepts related to the circle could be introduced. Thereafter, the volume and area of the structure could be calculated. The mathematics remains unchanged, but the context becomes real and tangible. This example illustrates the possible transformation of part of an ordinary colonial curriculum into a recontextualised indigenised discussion of the same mathematics but from a different lens familiar to African students.

\section{Decolonising Math Curriculum through language}

A common response was that language was the way to decolonise the curriculum; most participants listed this as one possibility. But Zuma provided an alternative view. He felt that the community viewed African learners who could speak English as being more intelligent. He claimed that some African learners cannot identify simple idioms from their indigenous language. He further found that many teachers who spoke isiZulu had to turn to using English for the learners to understand what they were saying. This, he felt, was moving our children away from indigenous systems and society was becoming more modernised. Gese also felt that language was a problem and to overcome this, code switching in mathematics classrooms was essential.

\section{Participant reflections on a decolonisation task}

This research did not provide tangible empirical evidence of ways in which decolonisation could be implemented in schools in South Africa, but it did produce a collective consciousness that something has to be done. All participants showed a positive inclination towards incorporating tasks that indigenised the content. Sebastian recognised the significance of a recontextualised indigenised curriculum. Phatha admitted that more time must be spent on planning these activities and he made the significant point that decolonising the curriculum was not about eradicating Western and European mathematics and their influence but was about incorporating local knowledge systems and contexts into the teaching and learning events. He found that while he was struggling with identifying with a recontextualised mathematics curriculum, the learners were having greater fun as they worked in the garden or did tasks that involved events and items from their own surroundings. Here he included ideas about measuring the height of trees without climbing them. The learners used the distance between a given point and the foot of the tree, established the angle to the top of the tree using a clinometer which they constructed themselves and then calculated the height of the tree. Phatha also showed that creating sequences when planting in rows got the learners to think more than they normally would. $\mathrm{He}$ used a common problem to illustrate. He asked his learners to imagine that they had a square piece of land and that they wanted to plant 10 trees on all four sides. He asked them to determine how many trees they would need altogether. The learners first hypothesised what the solution was and then used stones to test their hypotheses. In general, he found that his learners said 40 but changed their minds when actually using the stones. But Phatha did reiterate that decolonising the curriculum did not mean that Western and European mathematics must be removed, and this is why he had them make a clinometer. Nombu 
supported these views by claiming that decolonising the curriculum does not have to shut out Western and European mathematics.

Shivanie felt that the decolonised curriculum activity used in her lesson led to an enthusiastic and excited class. She could not tell whether it was because of the novelty of the methods she used or whether the learners genuinely felt that this helped them understand the mathematics.

In reflecting on the work that he did, Musa eventually conceded that the current mathematics curriculum "does not relate to the real-life situations and experiences of the learners." $\mathrm{He}$ acknowledged that teachers can try to move from indigenous knowledge (what learners already know) to concrete knowledge (that which they experience) to more abstract knowledge (such as mathematical concepts). Musa felt that although he did not completely see the links between the different knowledges, "the activity changed him as a teacher."

Gese presented a useful argument in his conclusion in stating that "our ability to decolonise mathematics depends on our willingness to do it." Despite the resistance that some participants expressed, Gese did acknowledge that decolonisation would have to come with a personal desire to see change. Thula clearly enunciated that position. In her reflection, she voiced an opinion shared by all participants. She indicated that this exercise changed her perspective of education and her practice. Her engagement in this project and the act of reflecting on what she was doing in class made her aware of the kinds of knowledge she presented and the methodologies she used. She became convinced that the current curriculum in schools pays little or no attention to indigenous knowledge. Thula wanted a clear delineation to be made between Western and European mathematics and that of indigenous knowledge. Significantly, she accepted the role of an activist when she declared, "I would now have to become the agent of change."

\section{Discussion and Conclusion}

The responses from the participants showed an initial reluctance to change the way they currently teach. Many viewed mathematics as unchanging, producing standard single solutions. In engaging with the activity in this research, they found it difficult to find suitable examples of recontextualised indigenised ways of teaching the common mathematics prescribed in the CAPS curriculum. Some participants provided a few contexts that described particular shapes, but these could not be used very effectively in the teaching of higher order mathematics. Although the circular structures (kraals and cattle kraals) were proposed, participants could not show how they could be used to engage in the teaching of mathematical concepts.

The fact that participants chose to download pictures also indicated that these kraals were not easily found or readily available to them. This, in itself, meant that they had different layers of indigenous knowledge as determined by their age and location. Many of the participants admitted that they had never seen a kraal so, while these may well be associated with African culture and living, these structures are not necessarily being used so such an example may be unfamiliar to our learners in schools. Learners may, in fact, more easily identify a wheel from 
a bus which they see daily. However, a wheel, as used in transport, is not an African invention.

Although earlier in this paper, I said that Phatha was convinced that including indigenous knowledge would confuse the learners, of great importance is the fact that the participants found the exercise useful and it changed their way of looking at the teaching of mathematics and raised their consciousness about the cultural inscription embedded in what they teach. Their inability to recontextualise and indigenise mathematics does not mean that decolonisation is futile. What it does do, though, is alert us to the idea that decolonising without sufficient training and awareness may reduce the effort to a futile exercise. If these postgraduate students with knowledge of curriculum and its development struggled, then we can be sure that other teachers may also struggle. The effort to recontextualise and indigenise the curriculum must be started and expounded by curriculum developers at the highest level. The simplistic views of these respondents contributed only to the argument that cultural and indigenous deficiencies can become a huge hurdle.

In conclusion, the evidence showed that the respondents felt that there was indeed a dire need for us to decolonise the curriculum and they felt that the current Westernised and Eurocentric curriculum does affect learners. The participants tried hard to find strategies that could help to decolonise the curriculum. Since this was a first attempt, they did not produce sufficiently useful ways, but their examples showed that they tried. They researched and presented ideas in their classrooms and their feedback showed a positive response from their learners at school. This research raised the level of curricula consciousness of these teachers that had not previously existed.

I recommend that the Department of Basic Education consider creating curriculum materials that guide teachers through this process of indigenising and decolonising the curriculum. Teachers need to see and understand how the process could unfold in the classroom.

Additionally, the Department of Basic Education must revise the CAPS document in order to address the scarcity of ideas of indigenising the curriculum present in the document. I further recommend that teacher training institutions begin to incorporate the ideas of decolonising into all modules so that preservice teachers understand how this process works.

\section{References}

Barrett, H. C. (2007). Researching electronic portfolios and learner engagement: The Reflect Initiative. Journal of Adolescent \& Adult Literacy, 50(6), 436-449

Badat, S. (2008, March). Redressing the Colonial/Apartheid Legacy: Social equity, redress and Higher Education admissions in democratic South Africa. Paper presented at the conference on Affirmative Action in Higher Education in India, the United States and South Africa. Retrieved from https://core.ac.uk/download/pdf/49241219.pdf

Barwell, R. (2005) Ambiguity in the language classroom. Language and Education, 19(2), $118-126$ 
Bernstein, B. (1996). Pedagogy, symbolic control and identity: Theory, research, critique. London, UK: Taylor \& Francis.

Cobb, P. (1986). Contexts, goals, beliefs, and learning mathematics. For the Learning of Mathematics, 6(2), 2-9

Connell, R. (2016). Decolonising knowledge, democratising curriculum. Retrieved from https://www.uj.ac.za/faculties/humanities/sociology/PublishingImages/Pages/Seminar s/Raewyn\%20Connell's\%20Paper\%20on\%20Decolonisation\%20of\%20Knowledge.p df

de Beer, J., \& Petersen, N. (2016). Decolonisation of the science curriculum: A different perspective (\#Cookbook-Labs-Must-Fall). Proceedings from ISTE International Conference on Mathematics, Science and Technology Education. Towards Effective Teaching and Meaningful Learning in Mathematics, Science and Technology, UNISA, Pretoria, RSA. Retrieved from http://uir.unisa.ac.za/bitstream/handle/10500/22869/Josef\%20de\%20Beer\%2c\%20Ne al\%20Petersen.pdf? sequence=1\&isAllowed=y

Department of Basic Education. (2011). Curriculum and Assessments Policy Statements. Department of Basic Education. Retrieved from https://www.education.gov.za/Portals/0/CD/National\%20Curriculum\%20Statements \%20and\%20Vocational/CAPS\%20FET\%20_\%20MATHEMATICS\%20_\%20GR\%2 010-12\%20_\%20Web_1133.pdf?ver=2015-01-27-154314-253

Department of Higher Education and Training. (2015). Reflections on Higher Education Transformation. (2015). Discussion paper presented at the second National Higher Education Transformation Summit, Universities South Africa, International Conference Centre, Durban, KwaZulu-Natal. Retrieved from http://www.justice.gov.za/commissions/FeesHET/docs/2015-HESummitAnnexure05.pdf

Department of Science and Technology. (2004). Indigenous Knowledge Systems. Retrieved from https://www.dst.gov.za/images/pdfs/IKS_Policy\%20PDF.pdf

Fataar, A. (2018). Decolonising Education in South Africa: Perspectives and debates. Educational Research for Social Change, 7, vi-ix

Heleta, S. (2016). Decolonization of higher education: Dismantling epistemic violence and Eurocentrism in South Africa. Transformation in Higher Education, 1(1), 1-8

Joseph, G. G. (1987). Foundations of Eurocentrism in mathematics. Race \& Class, XXVII (3), 13-28. Retrieved from http://citeseerx.ist.psu.edu/viewdoc/download?doi=10.1.1.900.4135\&rep=rep1\&type= pdf 
Kaya, H. O., \& Seleti, Y. N. (2013). African indigenous knowledge systems and relevance of higher education in South Africa. The International Education Journal: Comparative Perspectives, 12(1), 30-44

Kincheloe, J. L. (2007). Research in Educational Psychology: Incorporating the Bricolage in Educational Psychology_Part 1. In J. L. Kincheloe \& R. A. Horn Jr. (Eds.), The Praeger Handbook of Education and Psychology (Vols 1-4, pp. 943-949). Westport, CT: Praeger.

Kincheloe, J. L. (2011). Critical ontology and indigenous ways of being: Forging a postcolonial curriculum. In J. L. Kincheloe, K. Hayes, S. R. Steinberg \& K. Tobin (Eds.), Key works in critical pedagogy (pp. 333-348). Rotterdam, NL: Sense.

Mbembe, A. J. (2015). Decolonising knowledge and the question of the archive [lecture]. Wits Institute for Social and Economic Research, Johannesburg, RSA. Retrieved from https://wiser.wits.ac.za/sites/default/files/private/Achille\%20Mbembe\%20$\%$ 20Decolonizing\%20Knowledge\%20and\%20the \%20Question\%20 of $\% 20$ the $\% 20$ Arc hive.pdf

Mbembe, A. J. (2016). Decolonizing the university: New directions. Arts \& Humanities in Higher Education, 15(1) 29-45.

Studley, J. (1998). Dominant knowledge systems and local knowledge. Community-Based Mountain Tourism: Practices for linking conservation with enterprise. [Electronic conference, April 13 - May 18, 1998] The Mountain Forum. Retrieved from https://www.researchgate.net/publication/263657323_Dominant_Knowledge_System s_Local_Knowledge?enrichId=rgreq-a2116342cdef5137dcb749f4a876d17bXXX\&enrichSource=Y292ZXJQYWdlOzI2MzY1NzMyMztBUzo2NTgwMDUxMjk 0NDUzNzhAMTUzMzg5MjA1Njg1OQ\%3D\%3D\&el=1_x_2\&_esc=publicationCov erPdf

Vithal, R., \& Volmink, J. (2005). Mathematics curriculum research: Roots, reforms, reconciliation and relevance. In R. Vithal, J. Adler \& C. Keitel (Eds), Researching mathematics education in South Africa perspectives, practices and possibilities (pp. 3-27). Cape Town, RSA: Human Sciences Research Council.

Young, M. (2011). Curriculum policies for a knowledge society? In L. Yates \& M. Grumet (Eds.), Curriculum in today's world: Configuring knowledge, identities, work and politics (pp. 125-138). New York, NY: Routledge. 


\section{Appendix A}

\section{Curriculum Studies in Science and Mathematics Education BEd Honours Programme}

\section{Assessment}

South African teachers have experienced numerous planned educational changes during the past two decades. These changes have been embedded in a social justice framework. One of the aims of the Constitution is "to improve the quality of life of all citizens and free the potential of each person." The curriculum is viewed as a vehicle through which to achieve this, and, to this effect, the Curriculum Assessments Policy Statement (CAPS) includes the flowing principles: "Social transformation: ensuring that the educational imbalances of the past are redressed, and that equal educational opportunities are provided for all sections of the population" and "Human rights, inclusivity, environmental and social justice: infusing the principles and practices of social and environmental justice and human rights as defined in the Constitution of the Republic of South Africa. The National Curriculum Statement Grades $\mathrm{R}-12$ is sensitive to issues of diversity such as poverty, inequality, race, gender, language, age, disability and other factors." However, analysts argue that the curriculum continues to be embedded in colonial, apartheid-based, and Western worldviews.

In this assessment task, you are required to interrogate policy documents and subject materials and develop a unit of work that clearly illustrates how you can take steps towards decolonising the curriculum.

Begin by reading the articles in your course pack.

Develop a portfolio of evidence based on the information below.

1. Discuss what you understand by a "colonised" education system. (Do not write this in your portfolio.)

2. Discuss the concept of "epistemic violence." (Do not write this in your portfolio.)

3. Work in pairs. Select a unit of work from the Science or Mathematics curriculum or textbooks or other documents. Analyse it carefully and describe how this unit of work promotes colonial ways of thinking. You might want to show whether interests of a particular race group are promoted, whether inequality is perpetuated, whether specific knowledge systems are valued above all other forms of knowledge, what picture of Africa the curriculum paints, and whether certain people continue to be subjugated.

4. Re-design the unit of work to show how you could decolonise the curriculum.

5. Present your work. Your presentation should include:

5.1. Two key elements of the unit you selected which show that the unit reflects a colonised curriculum

5.2. Possible effects of these colonising elements on the learner/ community/ society/ country 
5.3. A description of how you would redesign the unit of work to align it to a decolonised curriculum.

6. Develop a lesson plan which incorporates one or two of the elements of the decolonised curriculum (mentioned in 6.3).

7. Teach the lesson according to your plan.

8. Develop four photo narratives to show how this decolonised unit of work was implemented.

9. Reflect on this task. Has is changed you as a teacher? How and Why? Do you think it is valuable from the perspective of a researcher? What was the most important learning point for you? 